\title{
A novel transport assimilation method for the Atlantic meridional overturning circulation at $26^{\circ} \mathrm{N}$
}

Article

Accepted Version

Hermanson, L., Dunstone, N., Haines, K., Robson, J., Smith, D. and Sutton, R. (2014) A novel transport assimilation method for the Atlantic meridional overturning circulation at $26^{\circ} \mathrm{N}$. Quarterly Journal of the Royal Meteorological Society, 140 (685). pp. 2563-2572. ISSN 1477-870X doi:

https://doi.org/10.1002/qj.2321 Available at https://centaur.reading.ac.uk/39078/

It is advisable to refer to the publisher's version if you intend to cite from the work. See Guidance on citing.

Published version at: http://dx.doi.org/10.1002/qj.2321

To link to this article DOI: http://dx.doi.org/10.1002/qj.2321

Publisher: Royal Meteorological Society

All outputs in CentAUR are protected by Intellectual Property Rights law, including copyright law. Copyright and IPR is retained by the creators or other copyright holders. Terms and conditions for use of this material are defined in the End User Agreement. 


\section{CentAUR}

Central Archive at the University of Reading

Reading's research outputs online 


\title{
A novel transport assimilation method for the Atlantic Meridional Overturning Circulation at $26^{\circ} \mathrm{N}$
}

\author{
Leon Hermanson ${ }^{1,2}$, Nick Dunstone ${ }^{3}$, Keith Haines ${ }^{1}$, Jon Robson ${ }^{1}$, \\ Doug Smith ${ }^{3}$, Rowan Sutton ${ }^{1}$ \\ ${ }^{1}$ University of Reading, Reading, UK \\ 2 Now at Met Office, Exeter, UK \\ ${ }^{3}$ Met Office, Exeter, UK
}

\begin{abstract}
One of the prerequisites for achieving skill in decadal climate prediction is to successfully initialise and predict the circulation in the Atlantic Ocean. The RAPID array measures the Atlantic Meridional Overturning Circulation (MOC) at $26^{\circ} \mathrm{N}$. Here we develop a method to include these observations in the UK Met Office Decadal Prediction System (DePreSys). The proposed method uses covariances of overturning transport at $26^{\circ} \mathrm{N}$ with ocean temperature and salinity throughout the ocean to create the density structure necessary to reproduce the observed transport. Assimilating transport alone in this way effectivly reproduces the observed transport at $26^{\circ} \mathrm{N}$, and is better than using basinwide temperature and salinity observations only. However, when the transport observations are combined with insitu tempertature and salinity observations in the analysis, the transport is not currently reproduced as well. The reasons for this are investigated using pseudo-observations in a twin experiment framework. Sensitivity experiments are used to show that the MOC at monthly time scales in this model is modulated by a mechanism where non-local density anomalies appear to be more important for transport variability at $26^{\circ} \mathrm{N}$ than local density gradients. This may not be the case in a different model.
\end{abstract}

\section{Introduction}

The RAPID transport array at $26^{\circ} \mathrm{N}$ in the Atlantic (Cunningham et al., 2007) is now providing a time series of one of the key components of the global ocean circulation, the Atlantic Meridional Overturning Circulation (MOC). Many modelling and observational studies suggest that this circulation plays an important role in climate variability and change, for example see Knight et al. (2005); Sutton and Hodson (2007); Rashid et al. (2010). To make best use of the RAPID data it is important to assimilate them into numerical models of the ocean and climate system to understand the changes that are seen and also to use the measurements to initialise future climate predictions.

However, how to assimilate these observations into a coupled climate model is not straightforward. The measurement components of the RAPID data consist of temperature and salinity profiles at the moorings, the cable monitored mass transport through the Florida Straits and wind-driven Ekman transport. The RAPID moorings are, intentionally, very close to the coastline where there is strongly varying topography. The numerical models that are used to simulate and predict ocean circulation do not usually resolve this detail well, making it hard to decide exactly how to assimilate the raw measurements. These models may also show significant biases in detailed aspects of the flow, even if they have reasonably realistic representation of some of the MOC variability, eg. Smith et al. (2010); Pohlmann et al. (2012); Roberts et al. (2013).

There have been earlier attempts to assimilate the RAPID data. Baehr (2010) used one year of observations from the cable as well as estimates of mid-ocean transport and profile components in a ECCO-GODAE state estimate. Stepanov et al. (2012) used the observed temperature and salinity of the RAPID moorings with boundary focussed covariances, but they did not use transports directly. The RAPID total MOC transport at $26^{\circ} \mathrm{N}$ is perhaps the most important quantity derived from the RAPID 
array and it is of interest to know if this transport can be assimilated directly into a climate model to induce similar MOC variability. Ideally, the MOC transport should be assimilated in a way that is fully compatible with the model, therefore avoiding trying to control details of the circulation that are not properly represented near the ocean model boundaries.

Relaxing velocities directly into models is likely to cause shocks as geostrophic balance will be disturbed in the mid-latitudes and the circulation will tend to re-adjust to the density distribution. Here we investigate a novel approach where transport-specific 3-D covariances with the temperature \& salinity distributions are used to introduce density variations with the intention of introducing balanced transport anomalies into the UK Met Office Decadal Prediction System (DePreSys). The advantages of using the DePreSys system are that it is a coupled system already in use for decadal prediction and also, because it is an anomaly assimilation system, MOC transport anomalies from the RAPID array can be assimilated without further concerns about model biases. We present results from using the RAPID observations to demonstrate that the method can be used with real observations. We also use an idealised twin experiment set-up as in Dunstone and Smith (2010) and Dunstone et al. (2011) to enable a fuller understanding of the performance of the method since the truth is always known.

The methodology is presented in the next section. In section 3 the transport covariances are presented and we discuss the physical mechanisms that shape them. In section 4 the results from the assimilation experiments are presented and we show how transport is introduced into the assimilations. The results are discussed in section 5 and our conclusions are in section 6 .

\section{The UK Met Office Decadal Prediction System (DePreSys)}

DePreSys is the UK Met Office experimental forecasting system (Smith et al., 2007) for inter-annual to multi-decadal time scales. The configuration in this study uses the HadCM3 model (Gordon et al., 2000; Pope et al., 2000; Collins et al., 2001). There are three stages: analysis, assimilation \& forecast. The analysis stage (Smith and Murphy, 2007) uses the observations in an optimal interpolation based scheme to produce global monthly-mean temperature and salinity fields on the model grid. Importantly, model-derived 3-D covariances are used to propagate information into sparsely observed regions. The covariances are global and extend over multiple levels, so a single observation can give a complete estimate of temperature and salinity. The assimilation stage then strongly relaxes model fields to the analysed fields. Finally, the forecasts use the assimilation output as initial conditions for coupled model prediction. Because of model biases, the assimilation system uses an anomaly assimilation method in which only the deviations of a measurement from an average seasonal cycle are introduced into the model. More specifically, at each time step the model is relaxed to the linear interpolation of the monthly-mean anomalies plus the model's own climatology. Assimilating anomalies has the advantage of reducing the shocks and the model drifts when the predictions are initialised, but it has the disadvantage, for our purposes, of requiring a reasonably long time series of observations in order to define the observed anomalies (the RAPID array monitoring was only introduced in 2004).

Here we introduce transport as a new type of observation into the DePreSys analysis and study the impacts on the assimilation. The resolution of the ocean model is $1.25^{\circ} \times 1.25^{\circ}$, so the bathymetry is very different from the real ocean, for example there is no Florida Straits. We therefore use transport covariances with ocean temperature \& salinity that are specific to our model. Assimilating the anomalous temperature and salinity structure will never reproduce the details of the transport (eg. the exact northward component observed in the Florida Straits), but the anomalous total transport at $26^{\circ} \mathrm{N}$ can be close to the observed.

In addition to the RAPID data, we use an idealised approach already used by Dunstone et al. (2011) to study the impact of sub-surface ocean data on decadal climate predictions. No atmospheric data are assimilated. The idealised approach provides complete knowledge of the target state for the assimilation and it eliminates the problems with model biases or defining a suitable observational climatology for the transport. It also means that the model covariances used in the analysis are the same as the ones in the system we are "observing". Therefore the results are easier to interpret and can help to understand the method.

The DePreSys system has been used for decadal predictions at the Met Office with calibration based on about 50 years of widespread subsurface ocean observations. So for the development of covariances in this study we have also used 50 year periods. We use ten well separated 50-year sections of a fully 
spun-up control integration of the HadCM3 climate model to calculate climatologies and covariances. For each assimilation experiment we take pseudo-observations from a 12 month period directly following each 50-year period, starting with December and ending with November the following year.

Although DePreSys is a decadal prediction system, we are in this paper primarily interested in initialising the monthly to annual time scales. This is partly because DePreSys uses monthly anomalies in its assimilation and partly because at the time this work was started, there were fewer than 4 years of RAPID observations available.

\section{Calculating transport covariances}

The transport covariances are the key to the transport assimilation method studied in this paper. As the DePreSys assimilation relaxes to ocean temperature and salinity, the covariances needed are those that link transport at $26^{\circ} \mathrm{N}$ to these fields basin-wide. The aim is to use optimal interpolation with these covariances to set up density gradients that, when assimilated, will give the desired transport anomaly. These density gradients are analogous to the gradients that are sampled by vertical profiles at $26^{\circ} \mathrm{N}$ in the Atlantic to calculate the upper mid-ocean overturning transport for the RAPID array (Hirschi et al., 2003) and also in two models (Baehr et al., 2004; Hirschi and Marotzke, 2007).

One of the advantages of this approach is that, by using model covariances, the density gradients associated with the MOC particular to this model are reproduced, thus maximising the chance that the transport is also reproduced. In a real-world situation assimilating the observed density gradients may not give the correct transport due to model biases (eg. an insufficiently strong western boundary intensification or an unresolved Florida Straits, as in the model used here). In the rest of this section, the correlations that correspond to the covariances used are presented, followed by an investigation into the likely physical mechanisms that control the MOC at $26^{\circ} \mathrm{N}$ implied by the correlations.

\subsection{Transport correlations}

The transport used in the calculation of the correlations is based on the total integrated meridional velocity down to $1000 \mathrm{~m}$ for the whole Atlantic cross-section at $26^{\circ} \mathrm{N}$, including the Gulf of Mexico, minus the wind-driven Ekman transport at this latitude. The Gulf of Mexico is included as the model does not have a landmass corresponding to Florida in the bathymetry and therefore there could be a net transport through the Gulf. The Ekman transport is calculated, as in (Cunningham et al., 2007), from the zonal wind stress and is contained in the Ekman layer (taken here to be in the top 80m) and compensated by a barotropic return flow. The main reason for removing the Ekman component is that we consider that the atmosphere is inherently less predictable than internal ocean processes on longer than monthly time scales (Griffies and Bryan, 1997) and we want to understand and initialise the predictable transport.

Figure 1 shows the zero-lag correlation between MOC minus Ekman transport at $26^{\circ} \mathrm{N}$ and temperature, salinity or density at $1100 \mathrm{~m}$ for a sample of two 50-year periods (top two rows). The standard deviation for all ten such periods is shown in the bottom row. The correlations are calculated from 600 monthly mean fields ( 50 years of 12 months) after the seasonal cycle has been removed from both transport and the other field. There are substantial differences between both individual periods. However, the standard deviation between the 50-year periods is low along the western boundary and off the coast of Africa. In density particularly, it is also low in the mid-ocean between $30^{\circ} \mathrm{N}$ and $40^{\circ} \mathrm{N}$.

We hypothesize that the correlations for individual 50-year sections contain some random component (for example from local trends) and that the mean correlations of all ten sections will better represent the leading physical processes that control the transport on monthly time scales.

\subsection{Implied mechanisms of model MOC variability}

To understand whether the correlations found do indeed have physical origins, this section analyses a little closer the mechanisms implied by the correlations.

Figure 2 shows the zonal and meridional wind stress correlation (given by the zonal and meridional components of the arrows) with MOC minus Ekman transport at $26^{\circ} \mathrm{N}$ for several lags (averaged over all ten periods), where wind stress leads transport. The shading in the figure shows the magnitude of the wind stress correlation. It is clear that at all lags shown, except one month before an MOC maximum, 
wind stress is strongly correlated with transport in the model. At lag -3 months, there is a cyclonic anomaly centred around $300^{\circ} \mathrm{E}$ and $34^{\circ} \mathrm{N}$, which will induce Ekman pumping in the region. This signal weakens gradually and disappears by lag -1 month. At lag 0 many surface winds are reversed and there are along-shore winds, which lead to coastal upwelling at $26^{\circ} \mathrm{N}$ on the western edge of basin and downwelling on the eastern edge (though the latter is weak). The coastal upwelling and downwelling strengthens the negative zonal density gradient related to northward ocean transport as mentioned above. At positive lags (not shown) the correlation between wind stress and transport is relatively small.

Lead-lag relationships between transport and density at $1000 \mathrm{~m}$ are shown in Figure 3 . At -6 months (density leading) positive density anomalies are visible at $40^{\circ} \mathrm{N}$ on the western boundary. At -4 and -2 months these move southward and the Ekman pumping seen in the winds induces lifting of isopycnals (heave) at $34^{\circ} \mathrm{N}$. The change in the mean zonal density gradient at $26^{\circ} \mathrm{N}$ for lag 0 as implied by the density correlations would exaggerate the existing difference in density between the two boundaries and induce a stronger geostrophic MOC.

At positive lags (transport leading) density anomalies persist along the western boundary, eventually exciting waves similar to equatorial and Rossby-like waves on the eastern boundary at +2 and +4 lags $\left(0-10^{\circ} \mathrm{N}\right.$ in the bottom two panels of Figure 3$)$. Correlations of transport with ocean temperature and salinity (not shown) suggest that the density correlation at $34^{\circ} \mathrm{N}$ is indeed due to heave. The signal spreading down the western boundary is cold and fresh (probably partly due to coastal upwelling), with the former dominating the density variability. At $26^{\circ} \mathrm{N}$ on the eastern boundary the signal is warm and saline implying coastal downwelling.

The physical mechanisms described here have been arrived at by studying the correlations as described above. They appear to be plausible mechanisms, but of course they are only useful if the transport covariances help in the assimilation of transport. In the next section we show the results from such assimilations.

\section{Assimilation experiments}

Having investigated the correlations implied by the transport covariances, we now use these covariances in assimilation experiments that use real and idealised pseudo-observations. First, in section 4.1 we demonstate the ability of the method to recreate the observed transport, as well as examining the use the transport covariances in conjunction with EN3 observations (Ingleby and Huddleston, 2007). To understand better the results, we carry out idealised experiments where the full state of the ocean is known and problems with model biases are removed to get a clearer picture of how the transport covariances are driving the model MOC. This is sometimes known as a "twin experiment" (Dunstone and Smith, 2010; Brüdgam et al., 2013). For the reasons described in section 3.1, we use the MOC with the Ekman component removed.

In section 4.2, we compare using transport observations sampled from the model (pseudo-RAPID) to using temperature and salinity pseudo-observations sampled from the model locations of the RAPID array (at the longitude of southward flow in the west and at the eastern boundary, in addition to the midAtlantic ridge). Following this, in section 4.3 we use the transport pseudo-observations together with EN3-like temperature and salinity pseudo-observations (sampled according to the 2008 observational locations). Finally, in section 4.4 we explore how transport has been modified in the model by the covariances and try to explain some of the results from the assimilations.

\subsection{Assimilation of RAPID observations and EN3 observations}

We attempt here to assimilate the observed transport at $26^{\circ} \mathrm{N}$ alongside EN3 observations of ocean temperature and salinity. The results of three different configurations are shown in Figure 4 . These are using transport as the only observation (dotted), using EN3 only (dashed) and using both together (dashdot). Only using the observed transport results in a remarkably good reproduction in the assimilation of the observed monthly mean transport, the correlation is 0.88 over 60 months. This is better than only using EN3 observations, which results in a correlation of 0.50 .

Using both sets of observations does not improve on the reproduction of the transport compared to the EN3-only case, it makes it worse. This is a counter-intuitive result as more observations should result in a better analysis. However, this is under the assumption that perfect covariances are used, 
which we know is not true in this case. In addition, there is only a short time series of observations for a climatology from which to calculate the observed anomalies of transport. To understand how this assimilation system performs in the absence of these problems it is necessary to consider idealised experiments where pseudo-observations are sampled from a model control integration.

\subsection{Twin experiments with pseudo-RAPID observations}

We first consider an alternative to assimilating the transport, to see if the RAPID data is better used in a different way. The RAPID total transport at $26^{\circ} \mathrm{N}$ is a sum of several terms, one of which is the upper mid-ocean transport. It is calculated from geostrophic balance using boundary temperature and salinity profiles to give the zonal density gradients. We ask the question whether direct assimilation of these profiles is sufficient to recover the correct transport. This would mean that the transport covariances are not necessary. To investigate this, we performed two assimilation experiments. The first uses only pseudoobservations of MOC transport, which make use of the transport covariances discussed in section 3. The second uses only pseudo-observations of temperature and salinity at the locations of the RAPID profiles in the model, which are spread out globally by the covariances as described in section 2 . The assimilated transport RMSE for all ten start dates can be seen as a function of latitude in Figure 5 (green and red lines respectively) for (b) both monthly mean and (c) annual mean transport.

The transport-only assimilation performs better for both time scales in the tropics and up to about $35^{\circ} \mathrm{N}$. For annual mean MOC-Ek the error in assimilating transport-only is lower for most latitudes. It appears that the transport covariances are able to impose a transport in the model assimilation that is much closer to the original transport than is possible just assimilating temperature and salinity profiles at the boundaries. The two experiments cannot be directly compared as the transport-only assimilation has knowledge of both the Florida Straits and the mid-ocean transport, whereas the temperature and salinity profiles will only provide the upper mid-ocean component directly. However, it is conceivable that the other components could have emerged through the temperature \& salinity covariances with other locations.

\subsection{Twin experiments with pseudo-EN3 and pseudo-RAPID observations}

In this section we combine the transport pseudo-observations with temperature and salinity pseudoobservations from across the whole ocean. The pseudo-observations of temperature and salinity are taken from the same model states as the transport and are sampled according to the EN3 2008 observation locations for each of the 12 months.

Figure 5 shows the results from assimilating the pseudo-EN3 observations only (blue) compared to the pseudo-transport only (red). In (a) the time series of transport at $26^{\circ} \mathrm{N}$ for the 12 months in each of the 10 start dates is shown alongside the truth (the transport from the control integration). Each start date is separated by a veritcal dotted line to highlight that they are not consecutive. The RMSE for these assimilations and that for pseudo-EN3 together with transport (purple) are shown as function of latitude in the lower two panels of Figure 5. In the subtropical gyre $\left(20-30^{\circ} \mathrm{N}\right)$ assimilating $26^{\circ} \mathrm{N}$ MOC transport anomalies alone gives the best reproduction of the MOC-Ek for monthly and annual means, better than assimilating pseudo-EN3 or the combination of the two. At latitudes above $35^{\circ} \mathrm{N}$ assimilating $26^{\circ} \mathrm{N} \mathrm{MOC}$ pseudo-transport anomalies is not as successful as assimilating pseudo-EN3 data. The addition of RAPID pseudo-transports to the pseudo-EN3 data does not markedly improve the reproduction of the transport in the assimilation. It does not make it worse than the pseudo-EN3 only case either, in contrast to the results using real observations.

\subsection{Modifying transport in the assimilation}

Shown in Figure 5 (b) and (c) is a best case scenario (black line) where the exact monthly mean of pseudo-observations of salinity and temperature has been assimilated at all locations. The transport-only experiment (red line) has a lower or similar monthly mean RMSE than the 'best case' at and around $26^{\circ} \mathrm{N}$. The best case should have almost perfect monthly-mean density gradients with minor differences because the assimilation relaxes to ocean temperature and salinity monthly means (with linear interpolation between months) and that the equation of state for density is non-linear. How can the pseudo-transport only assimilation do as well or better than this? 
The intention of the method for assimilating transport is to improve density gradients in the model so that the correct geostrophic transport is induced. Is this what is happening? One way to answer this question is to look at the ability of the assimilation in reproducing the zonal density gradient at $26^{\circ} \mathrm{N}$. Figure 6 shows the RMSE of the zonal density gradient (defined as the density at the western boundary minus the density at the eastern boundary). Despite the pseudo-transport only assimilation producing better transport at $26^{\circ} \mathrm{N}$, its density gradient has the largest errors, which suggests that the tranport assimilation is not working due to constraining the large-scale baroclinic transport.

We carry out two sensitivity experiments to understand better why transport is so well reproduced for the transport-only assimilation, as it does not appear to be due to an improvement in the local density gradient (Figure 6). As shown in Figure 2, atmospheric wind variability is important for the MOC in this model. There is no assimilation in the atmosphere in these experiments, but assimilated SSTs could feed back through the atmosphere onto the MOC. Therefore in the first sensitivity experiment, "zero SST", the transport-only temperature and salinity fields are assimilated at all depths except the surface, where climatological fields are assimilated. Figure 7 shows that the impact of changing SSTs is small at and around $26^{\circ} \mathrm{N}$ in this assimilation (dark blue line), it has very similar RMSE to the transport-only assimilation (red line). We can therefore conclude that the improved reproduction of transport is not due to induced atmospheric variability. In the second sensitivity experiment, "zero $26 \mathrm{~N}$ ", we test the impact of assimilating anomalies away from $26^{\circ} \mathrm{N}$. The transport-only temperature and salinity fields were used everywhere apart from $23^{\circ} \mathrm{N}-29^{\circ} \mathrm{N}$ (as indicated by vertical lines in Figure 7) in the Atlantic, where climatological temperature and salinity fields were used at all depths. The error of the transport in this case (cyan line) is still similar to the transport-only assimilation at the northern end of this region $\left(27^{\circ} \mathrm{N}-29^{\circ} \mathrm{N}\right)$. In contrast, at the southern end $\left(23^{\circ} \mathrm{N}\right)$ the error is almost as high as when climatological fields are used everywhere (green line). This result implies that the reproduction of transport at $26^{\circ} \mathrm{N}$ is strongly dependent on information propagating into the grid-box from the North.

The importance of non-local anomalies and their impact at $26^{\circ} \mathrm{N}$ is now investigated further. Figure 8 (a) shows the RMSE of monthly mean velocity at $26^{\circ} \mathrm{N}$ in the pseudo-EN3-only experiment minus the RMSE in the pseudo-transport-only experiment (the difference in RMSE). Negative values indicate that transport-only has lower errors and this is mainly at depths below $700 \mathrm{~m}$. The lower errors at the eastern boundary are probably due to local changes in density as seen in Figure 3. We expect that boundary waves propagate from the South on this boundary (Johnson and Marshall, 2002) and so cannot be important as the "zero 26N" sensitivity study showed that information comes from the North. Therefore we focus on the western boundary. We define a meridional velocity index at $26^{\circ} \mathrm{N}$ by averaging over the area (weighted by level thickness) indicated by the black box in Figure $8(\mathrm{a})\left(283.75^{\circ} \mathrm{E}-286.25^{\circ} \mathrm{E}\right.$ and $700-3500 \mathrm{~m}$ ). This area encompasses the deep southern return flow of the MOC in the model. The mean correlation in the ten 50-year sections from the control run of this index and meridional velocity at other latitudes is shown in Figure 8(b) for 3,400m depth (the depth where the correlation is largest). It is clear that strong positive correlations exist along the western boundary up to and North of $34^{\circ} \mathrm{N}$. In addition, these correlations are strongest at zero lag (not shown), therefore the changes in velocity happen at time scales shorter than a month. Figure $8(\mathrm{c})$ shows the cross-section of the velocity correlations at $34^{\circ} \mathrm{N}$. These correlations are located adjacent to a maximum in the correlation between density and MOC-Ek, as used in the transport covariances, shown in a cross-section at $34^{\circ} \mathrm{N}$ in Figure $8(\mathrm{~d})$.

We hypothesize that in the transport-only assimilation density anomalies introduced further North, and especially at $34^{\circ} \mathrm{N}$, interact with the boundary and cause the generation of some kind of boundary waves that propagate rapidly to $26^{\circ} \mathrm{N}$. These waves propagate South and appear to reach $26^{\circ} \mathrm{N}$ within a month. Unfortunately, we do not have ocean fields on time scales short enough to study the exact shape of these waves. It is interesting to note that the barotropic (or external) part of the MOC is important at and around $26^{\circ} \mathrm{N}$ in HadCM3 (Sime et al., 2006), so the density anomalies may be projecting onto the barotropic mode. These density anomalies are probably caused by the wind anomalies seen in Figure 2 . This mechanism operates on time scales of one month or shorter, variability at longer time scales could have other causes.

\section{Discussion}

In this section, we consider why adding more observations does not improve the assimilation, then we discuss the possible limitations of the approach and to what extent is it likely to be more widely useful. 
Finally, there is a comment on the climatologically important heat transport.

The optimal interpolation scheme used here to prepare the analyses of temperature and salinity (Smith and Murphy, 2007) is dependent on assumptions of linear relationships and Gaussian distributions of the variables, but it is usually robust. So why does adding the temperature and salinity observations to the transport observations make the assimilated MOC worse? We are using covariances derived from a separate integration of the same model, so they are specific to the model being used. The correlations between transport and temperature \& salinity are small (Figure 1) so when analysing transport it gives small increments for temperature and salinity. Nonetheless, the cumulative effect of all these increments has the intended effect. When the temperature and salinity fields from the analysis of transport are assimilated, the transport is well reproduced, both for real observations and in the idealised cases.

For the case that only uses temperature and salinity observations, a good transport is also achieved in the assimilation, although not as good as the previous case probably because there are observations missing in key locations for the MOC. The increments for temperature and salinity are relatively much bigger for the temperature and salinity observations than they are for the transport observations. It is therefore perhaps not surprising that the transport in the assimilation for the case of transport combined with temperature \& salinity observations is not much different from using temperature \& salinity only as shown in Figure 5 for the idealised case. For the case of real observations (Figure 4), the combined case actually has a lower correlation with the observed time series than either of the two other cases. This is presumably because the model MOC is different (in location and its response to density anomalies on boundaries) to the observed MOC. In addition, there will most likely be errors in the climatology used to calculate the observed anomalies of transport leading to disagreement between them and the temperature \& salinity anomalies. So although the increments for temperature and salinity are small for transport, they may combine erroneously with the temperature \& salinity fields as these are not consistent. This could for example explain the large deviation in the MOC in June 2006 for the combined assimilation.

The advantage of this method is that it finds the most efficient way to control transport in the model. As we showed in section 3 calculating these covariances can help in understanding how the model variability is driven on average. In the case of HadCM3, the most efficent mechanism that alters the MOC at $26^{\circ} \mathrm{N}$ involves remote density anomalies. When setting up the experiments, we expected that local density anomalies would more important, but the sensitivity experiments in Figure 7 show that they are not. This might reflect the importance of the barotropic (or external) component for AMOC variability at this latitude in HadCM3 (Sime et al., 2006). In another model, the exact details of the mechanism could be different, but the method should still find the dominant driver of variability.

Any variable that is observed, but not generally assimilated could benefit from this method. However, caution is advised if the variable, as is our case, is an integrated variable. One value of the transport (a vertically and horizontally integrated quantity) can correspond to many different configurations of temperature and salinity. The one configuration present in the transport covariances does not necessarily correspond to the current configuration of temperature and salinity and may have limited the usefulness of this method. Wunsch and Heimbach (2013) come to a similar conclusion studying a 19-year long ocean state estimate.

The MOC is known to be important for interdecadal climate variability (Dong and Sutton, 2005). This is primarily through its link with the meridional heat transport (MHT, Jayne and Marotzke, 2002). We have calculated the skill scores in our idealised experiments for MHT, but do not present them as they do not differ in any meaningful way from the results in Figure 5: for monthly means between from $20^{\circ} \mathrm{N}$ to $30^{\circ} \mathrm{N}$ the transport-only assimilation has the smallest errors. The similarity with the MOC results is probably because there is a strong relationship between the MOC and the MHT in the model at this latitude, which echoes the results of Johns et al. (2011), who found a strong relationship in the RAPID data at $26.5^{\circ} \mathrm{N}$.

\section{Conclusions}

In this paper, we use covariances between transport and ocean temperature \& salinity to assimilate monthly-mean transport observations, such as those provided by the RAPID array, into a climate model (HadCM3). This is a previously uncommon variable to assimilate into ocean models and even more uncommon to assimilate into climate models. 
We also found that covariances calculated over 50-year periods between transport and ocean density are relatively noisy. When using several periods and averaging, physically relevant covariances emerge. This novel approach was preferred to using a longer time series as that would change the time scales of the processes represented by the covariances. It is known that on monthly time scales wind stress is an important driver of MOC variability at $26^{\circ} \mathrm{N}$ (Kanzow et al., 2010; Hirschi et al., 2007), we found this to be true for HadCM3 as well.

The method proposed here can be used successfully to assimilate observations from the RAPID array. For capturing transport, the method is better than assimilating temperature and salinity only, which shows promise for the use of such a method. However, when insitu temperature and salinity observations are also assimilated the impact of transport assimilation is lessened in the idealised case and makes the simulated transports worse in the real observation case. It is possible that this limitation can be overcome, further work is needed.

\section{References}

Baehr, J. (2010). Influence of the 26N RAPID-MOCHA Array and Florida Current Cable Observations on the ECCO-GODAE State Estimate. Journal of Physical Oceanography, 40(11), 865-879.

Baehr, J., Hirschi, J., Beismann, J.-O., and Marotzke, J. (2004). Monitoring the meridional overturning circulation in the North Atlantic: A model-based array design study. Journal of Marine Research, 62, $283-312$.

Brüdgam, M., Eden, C., Czeschel, L., and Baehr, J. (2013). The ability of the adjoint technique to recover decadal variability of the north atlantic circulation. Ocean Modelling, 69, 166 - 180.

Collins, M., Tett, S. F. B., and Cooper, C. (2001). The internal climate variability of HadCM3, a version of the Hadley Centre coupled model without flux adjustments. Climate Dynamics, 17, 61-81.

Cunningham, S. A., Kanzow, T., Rayner, D., Baringer, M. O., Johns, W. E., Marotzke, J., Longworth, H. R., Grant, E. M., Hirschi, J. J.-M., Beal, L. M., Meinen, C. S., and Bryden, H. L. (2007). Temporal variability of the Atlantic meridional overturning circulation at 26.5n. Science, 317, 935-938.

Dong, B. and Sutton, R. T. (2005). Mechanism of interdecadal thermohaline circulation variability in a coupled ocean-atmosphere GCM. Journal of Climate, 18, 1117-1135.

Dunstone, N. J. and Smith, D. M. (2010). Impact of atmosphere and sub-surface ocean data on decadal climate prediction. Geophysical Research Letters, 37, L02709. doi: 10.1029/2009GL041609.

Dunstone, N. J., Smith, D. M., and Eade, R. (2011). Multi-year predictability of the tropical Atlantic atmosphere driven by the high latitude North Atlantic Ocean. Geophysical Research Letters, 38, L14701. doi: 10.1029/2011GL047949.

Gordon, C., Cooper, C., Senior, C. A., Banks, H., Gregory, J. M., Johns, T. C., Mitchell, J. F. B., and Wood, R. A. (2000). The simulation of SST, sea ice extent and ocean heat transports in a version of the Hadley Centre coupled model without flux adjustments. Climate Dynamics, 16, 147-168.

Griffies, S. M. and Bryan, K. (1997). A predictability study of simulated North Atlantic multidecadal variability. Climate Dynamics, 13, 459-487.

Hirschi, J. and Marotzke, J. (2007). Reconstructing the Meridional Overturing Circulation from Boundary Densities and Zonal Wind Stress. Journal of Physical Oceanography, 37, 743-763.

Hirschi, J., Baehr, J., Marotzke, J., Stark, J., Cunningham, S., and Beismann, J.-O. (2003). A monitoring design for the Atlantic meridional overturning circulation. Geophysical Research Letters, 30, 1413. doi:10.1029/2002GL016776.

Hirschi, J. J.-M., Killworth, P. D., and Blundell, J. R. (2007). Subannual, Seasonal, and Interannual Variability of the North Atlantic Meridional Overturning Circulation. Journal of Physical Oceanography, 37, 1246-1265. 
Ingleby, B. and Huddleston, M. (2007). Quality control of ocean temperature and salinity profiles - historical and real-time data. Journal of Marine Systems, 65, 158-175. doi: 10.1016/j.jmarsys.2005.11.019.

Jayne, S. R. and Marotzke, J. (2002). The oceanic eddy heat transport. Journal of Physical Oceanography, 32, 3328-3345.

Johns, W. E., Baringer, M. O., and Coauthors (2011). Continuous, array-based estimates of atlantic ocean heat transport at 26.5N. Journal of Climate, 24, 2429-2449. doi: 10.1175/2010JCLI3997.1.

Johnson, H. L. and Marshall, D. P. (2002). A theory for the surface Atlantic response to thermohaline variability. Journal of Physical Oceanography, 32, 1121-1132.

Kanzow, T., Cunningham, S. A., Johns, W. E., Hirschi, J. J.-M., Marotzke, J., Baringer, M. O., Meinen, C. S., Chidichimo, M. P., Atkinson, C., Beal, L. M., Bryden, H. L., and Collins, J. (2010). Seasonal variability of the atlantic meridional overturning circulation at 26.5n. Journal of Climate, 23, 56785698.

Knight, J. R., Allan, R. J., Folland, C. K., Vellinga, M., and Mann, M. E. (2005). A signature of persistent natural thermohaline circulation cycles in observed climate. Geophysical Research Letters, 33, L20708. doi: $10.1029 / 2005$ GL024233.

Pohlmann, H., Smith, D. M., Balmaseda, M. A., Keenlyside, N. S., Masina, S., Matei, D., Mller, W. A., and Rogel, P. (2012). Predictability of the mid-latitude Atlantic meridional overturning circulation in a multimodel system. Climate Dynamics.

Pope, V. D., Galiani, M. L., Rowntree, P. R., and Stratton, R. A. (2000). The impact of new physical parametrisations in the Hadley Centre coupled model without flux adjustments. Climate Dynamics, 16, 123-146.

Rashid, H. A., Power, S. B., and Knight, J. R. (2010). Impact of multidecadal fluctuations in the Atlantic thermohaline circulation on indo-pacific climate variability in a coupled GCM. Journal of Climate, 23, 4038-4044. doi: 10.1175/2010JCLI3430.1.

Roberts, C. D., Waters, J., Peterson, K. A., Palmer, M. D., McCarthy, G. D., Frajka-Williams, E., Haines, K., Lea, D. J., Martin, M. J., Storkey, D., Blockley, E. W., and Zuo, H. (2013). Atmosphere drives recent interannual variability of the atlantic meridional overturning circulation at 26.5n. Geophysical Research Letters, accepted.

Sime, L. C., Stevens, D. P., Heywood, K. J., and Oliver, K. I. C. (2006). A decomposition of the Atlantic Meridional Overturning. Journal of Physical Oceanography, 36, 2253-2270.

Smith, D. M. and Murphy, J. M. (2007). An objective ocean temperature and salinity analysis using covariances from a global climate model. Journal of Geophysical Research, 122, C02022.

Smith, D. M., Cusack, S., Colman, A. W., Folland, C. K., Harris, G. R., and Murphy, J. M. (2007). Improved surface temperature prediction for the coming decade from a global climate model. Science, 317, 796-799.

Smith, G., Haines, K., Kanzow, T., and Cunningham, S. (2010). Impact of hydrographic data assimilation on the modelled Atlantic meridional overturning circulation. Ocean Science, 6, 761-774. doi: 10.5194/os-6-761-2010.

Stepanov, V. N., Haines, K., and Smith, G. C. (2012). Assimilation of RAPID array observations into an ocean model. Quarterly Journal of the Royal Meteorological Society. doi: 10.1002/qj.1945.

Sutton, R. T. and Hodson, D. L. R. (2007). Climate response to basin-scale warming and cooling of the North Atlantic Ocean. Journal of Climate, 20, 891-907. doi: 10.1175/JCLI4038.1.

Wunsch, C. and Heimbach, P. (2013). Two Decades of the Atlantic Meridional Overturning Circulation: Anatomy, Variations, Extremes, Prediction, and Overcoming Its Limitations. Journal of Climate. doi: 10.1175/JCLI-D-12-00478.1. 


\section{Temperature}
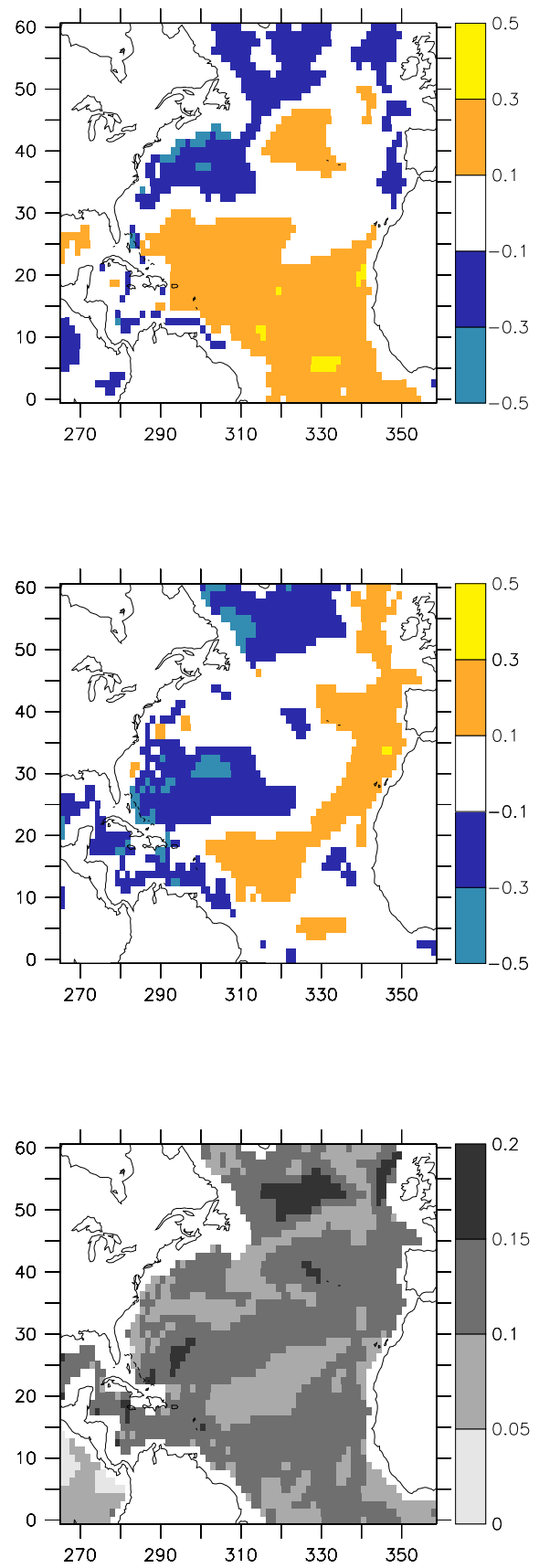

Salinity
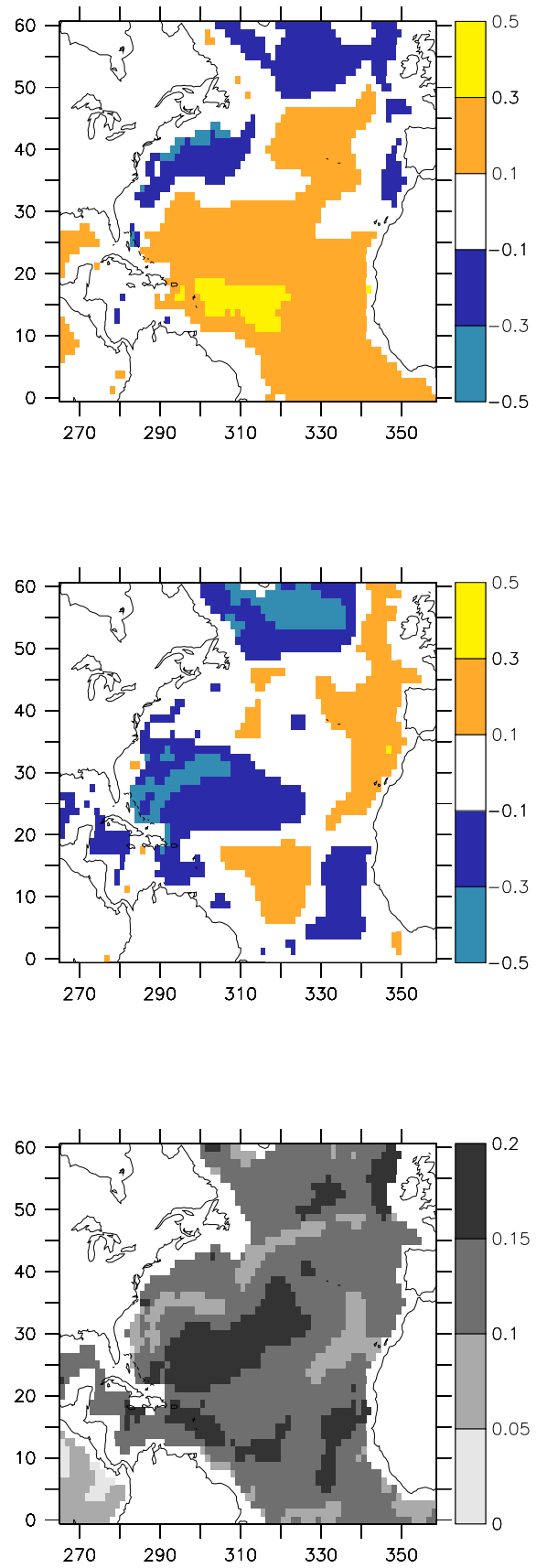

Density
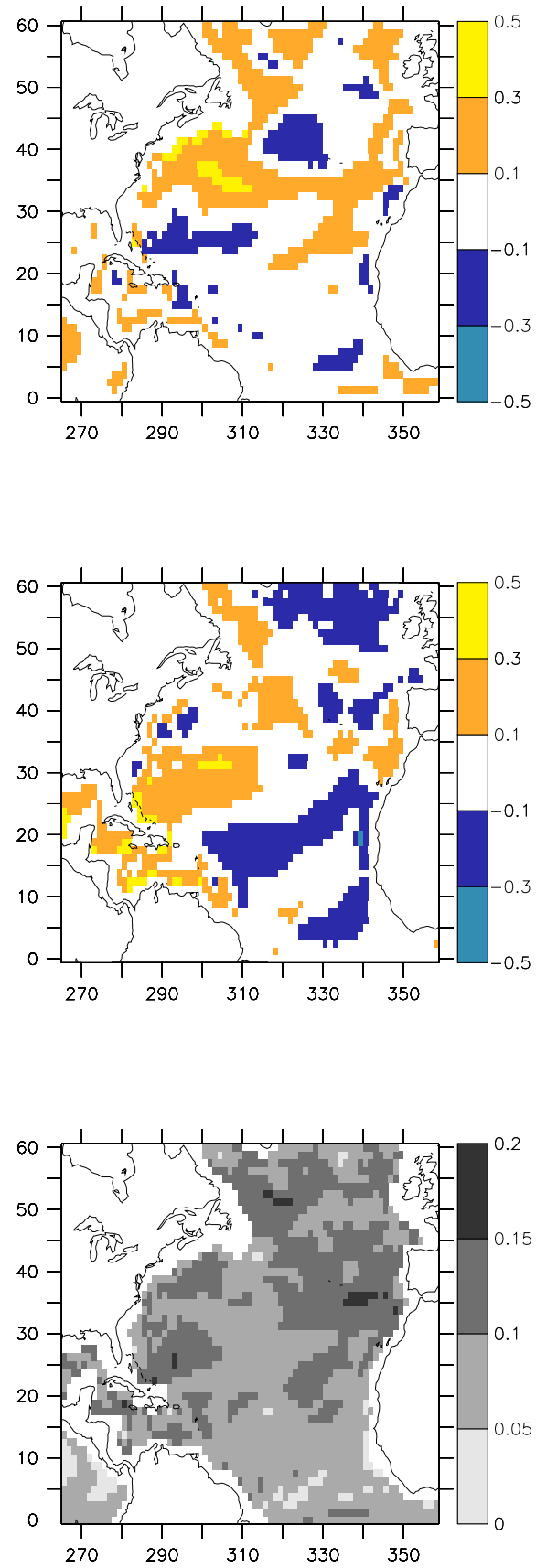

Figure 1: Correlations at zero lag between MOC minus Ekman transport at $26^{\circ} \mathrm{N}$ and ocean potential temperature (first column), salinity (second column) and density (third column) at 1100m for two (first and second row) well-separated 50-year periods of HadCM3 using monthly means (seasonal cycle removed) and the standard deviation of ten such periods (bottom row) 

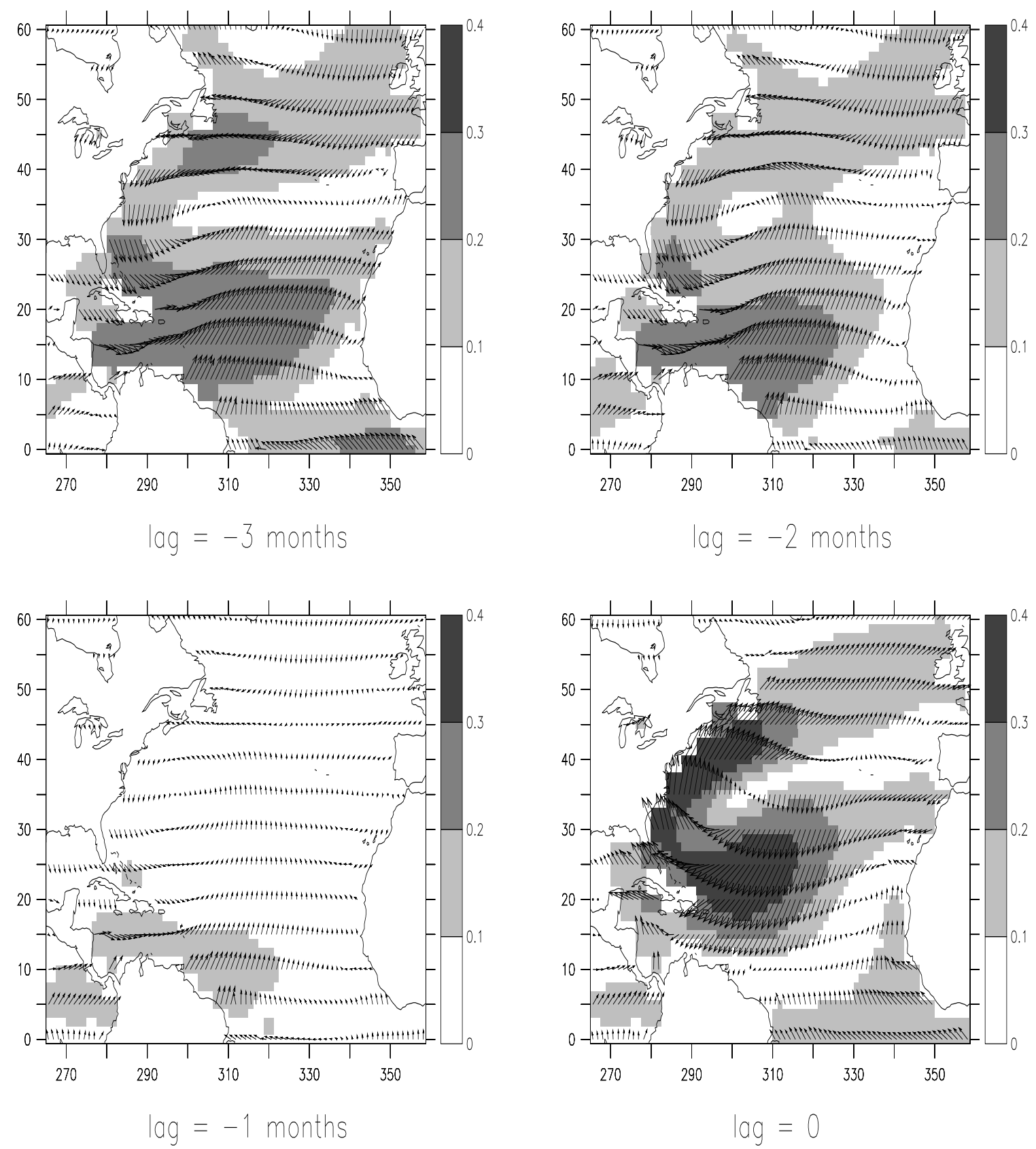

Figure 2: Mean correlations between MOC minus Ekman transport at $26^{\circ} \mathrm{N}$ and surface wind stress using monthly means (seasonal cycle removed). Arrows show correlation in the zonal and meridional component, shading shows magnitude of arrows. 

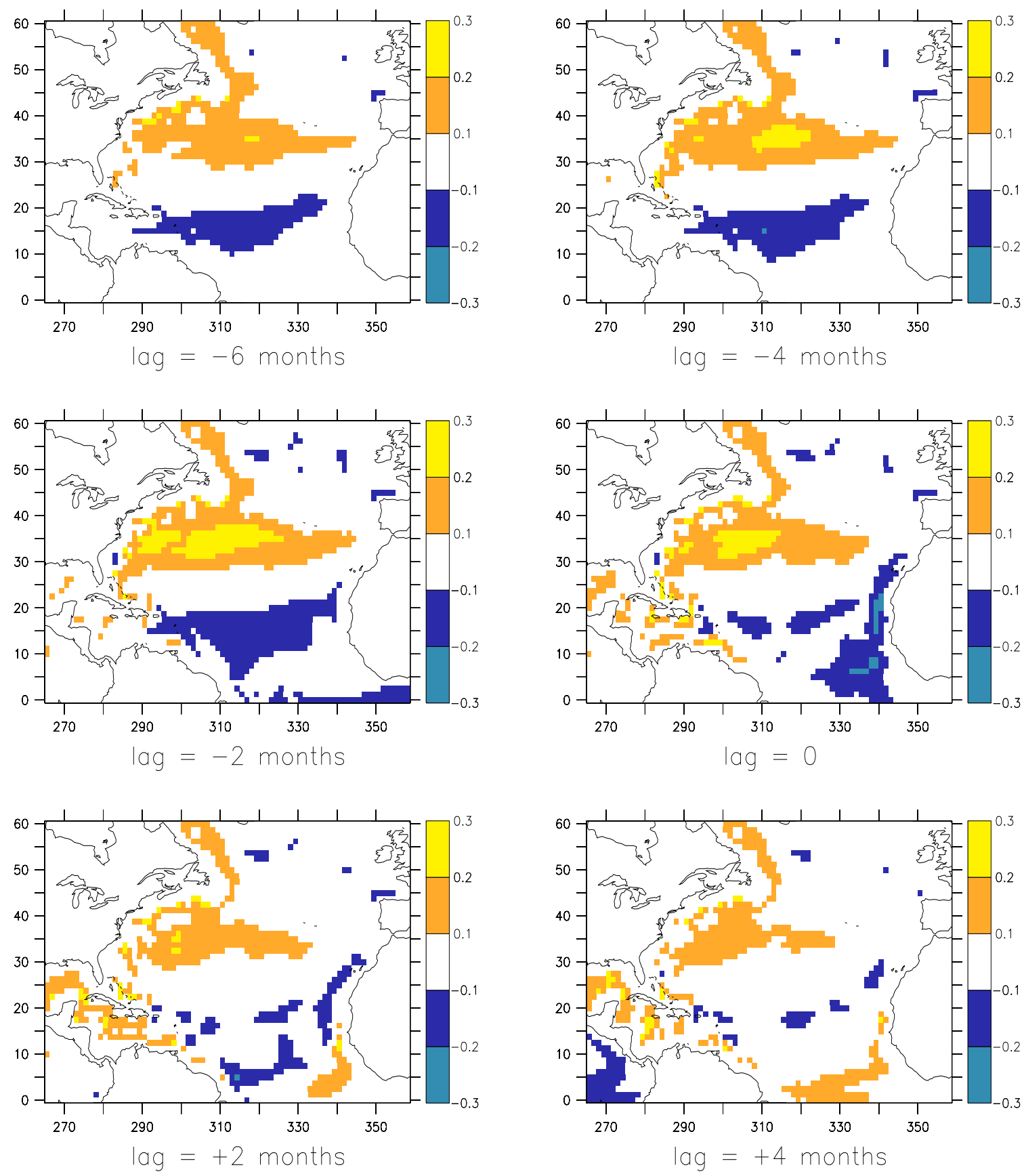

Figure 3: Lagged mean correlations between MOC minus Ekman transport at $26^{\circ} \mathrm{N}$ and density at $1100 \mathrm{~m}$ using monthly means (seasonal cycle removed). 


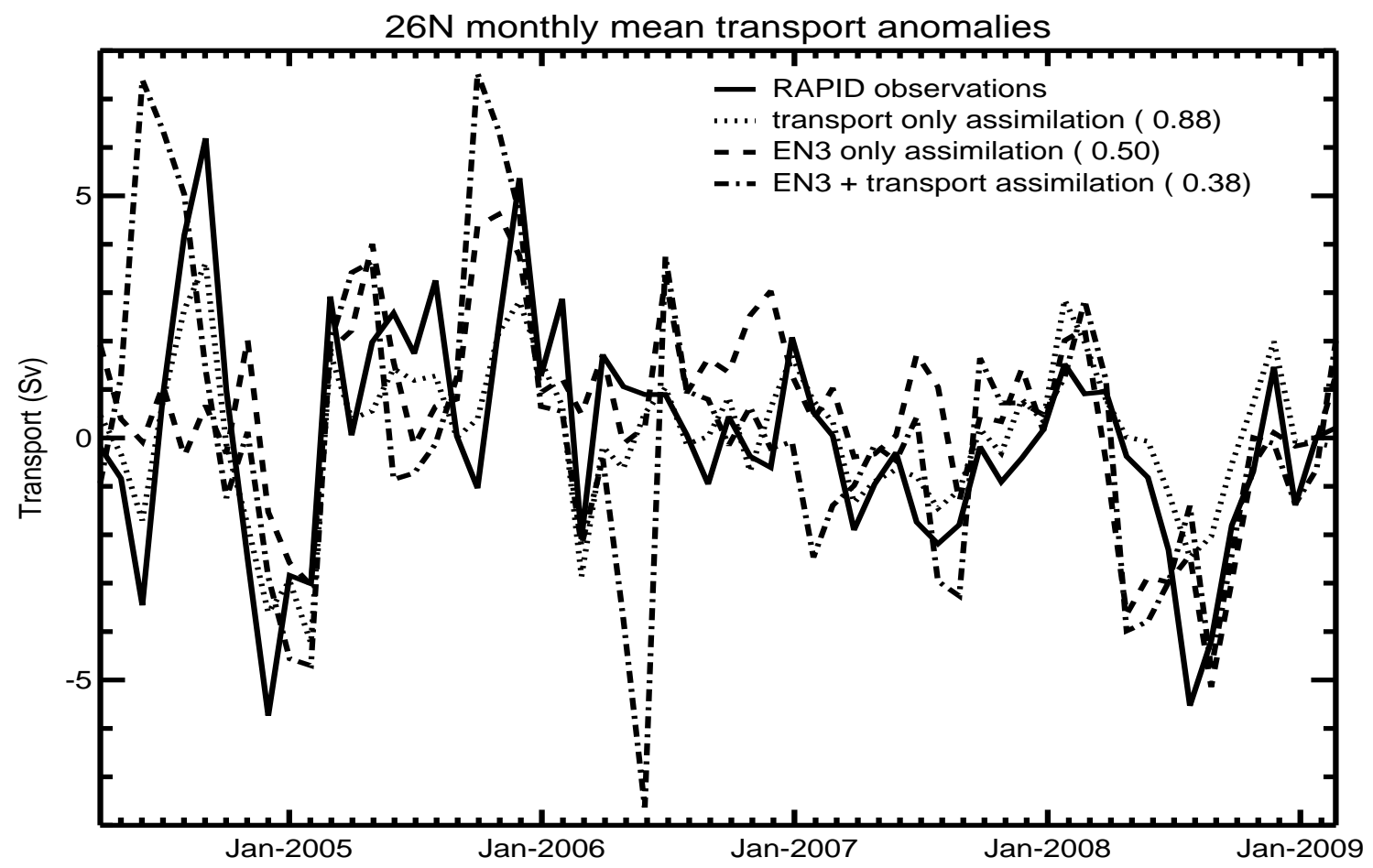

Figure 4: Monthly mean transport (MOC minus Ekman) anomalies for RAPID data (solid line), assimilation of transport only (dotted), assimilation of EN3 only (dashed) and assimilation of the combined transport and EN3 data set. 
(a) Anomaly MOC-Ek monthly means at $26 \mathrm{~N}$

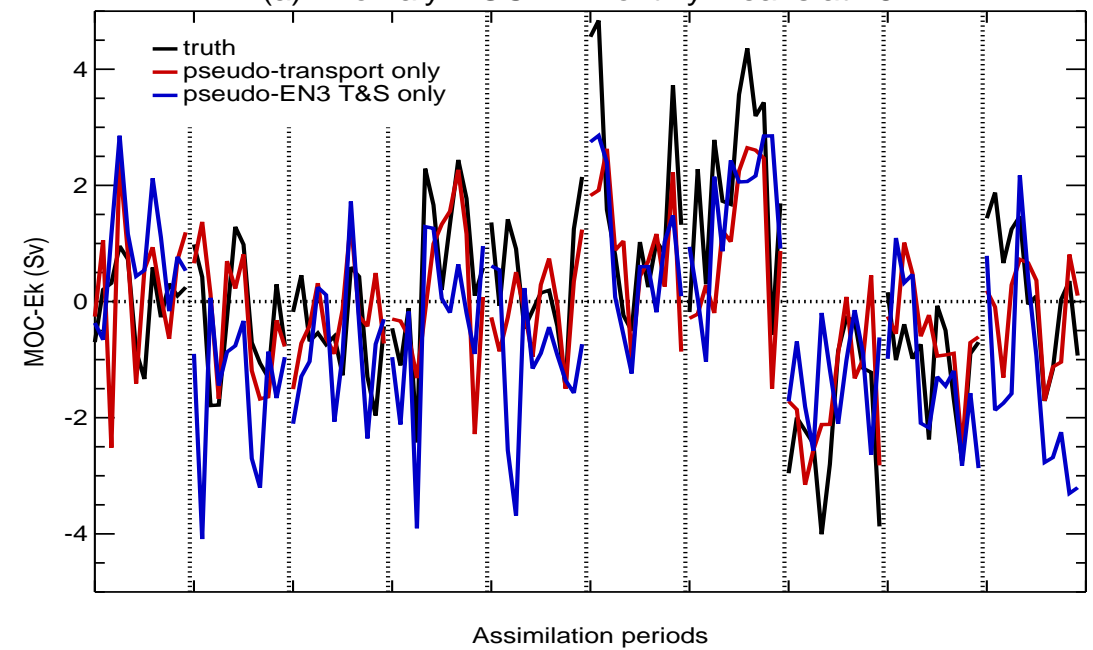

(b) Anomaly RMSE MOC-Ek monthly means

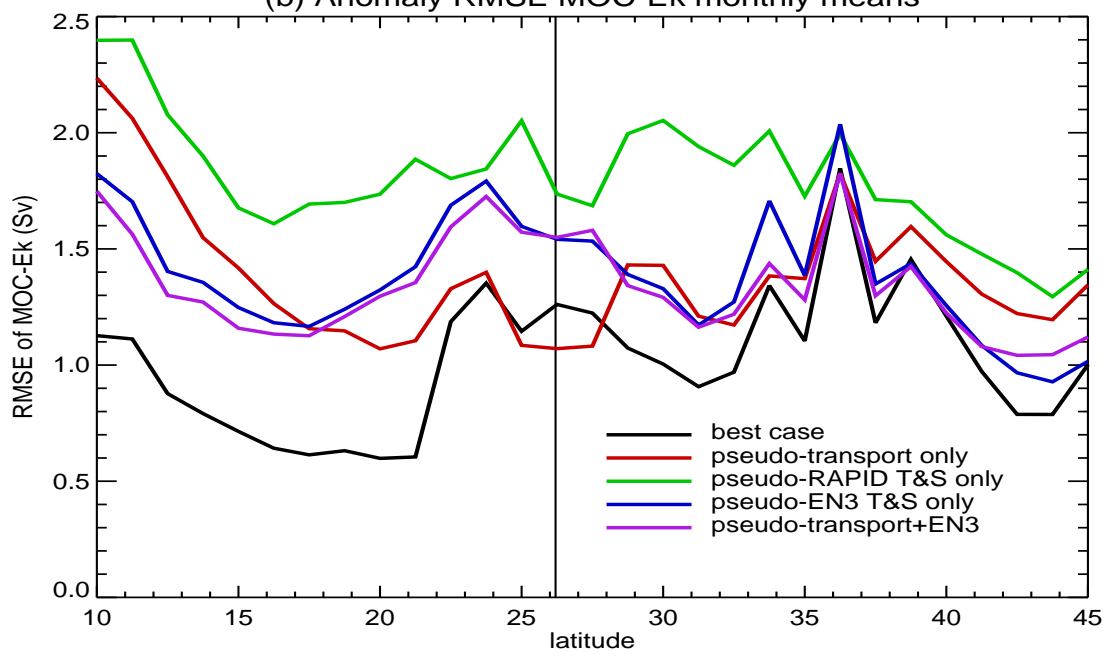

(c) Anomaly RMSE MOC-Ek annual means

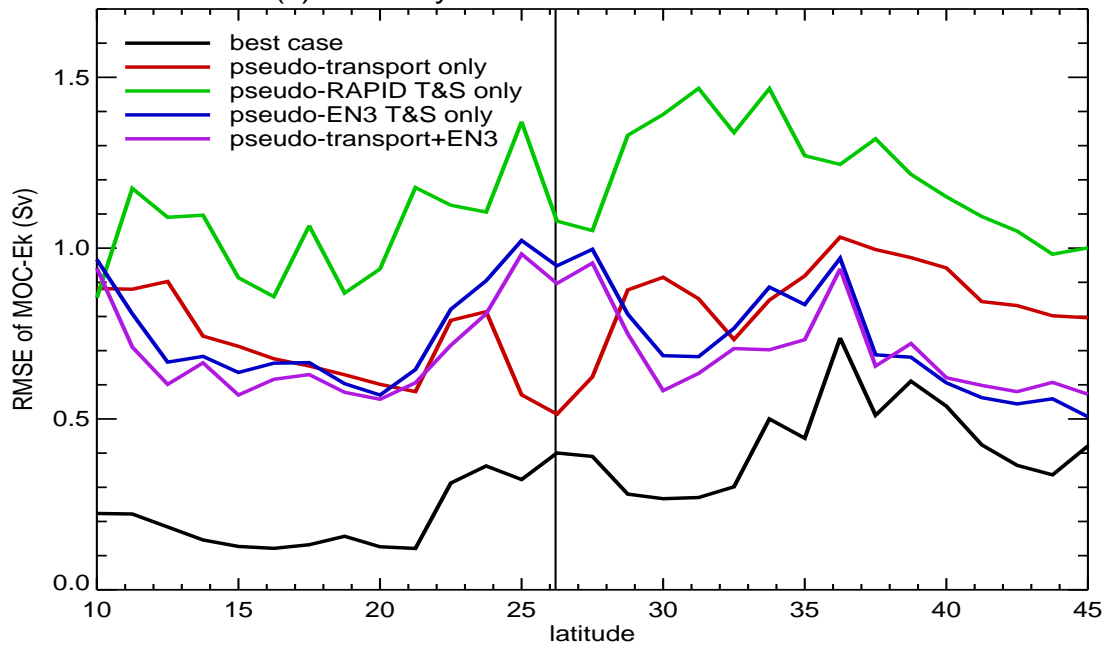

Figure 5: Results from idealised assimilation experiments. (a) shows the anomaly time series of transport at $26^{\circ} \mathrm{N}$ for the ten 12 -month periods assimilated. The lower two panels show RMSE in the assimilation of (b) monthly and (c) annual anomalies from the original transport as a function of latitude. The vertical line in (b) and (c) marks the latitude at which the transport observation was included. 

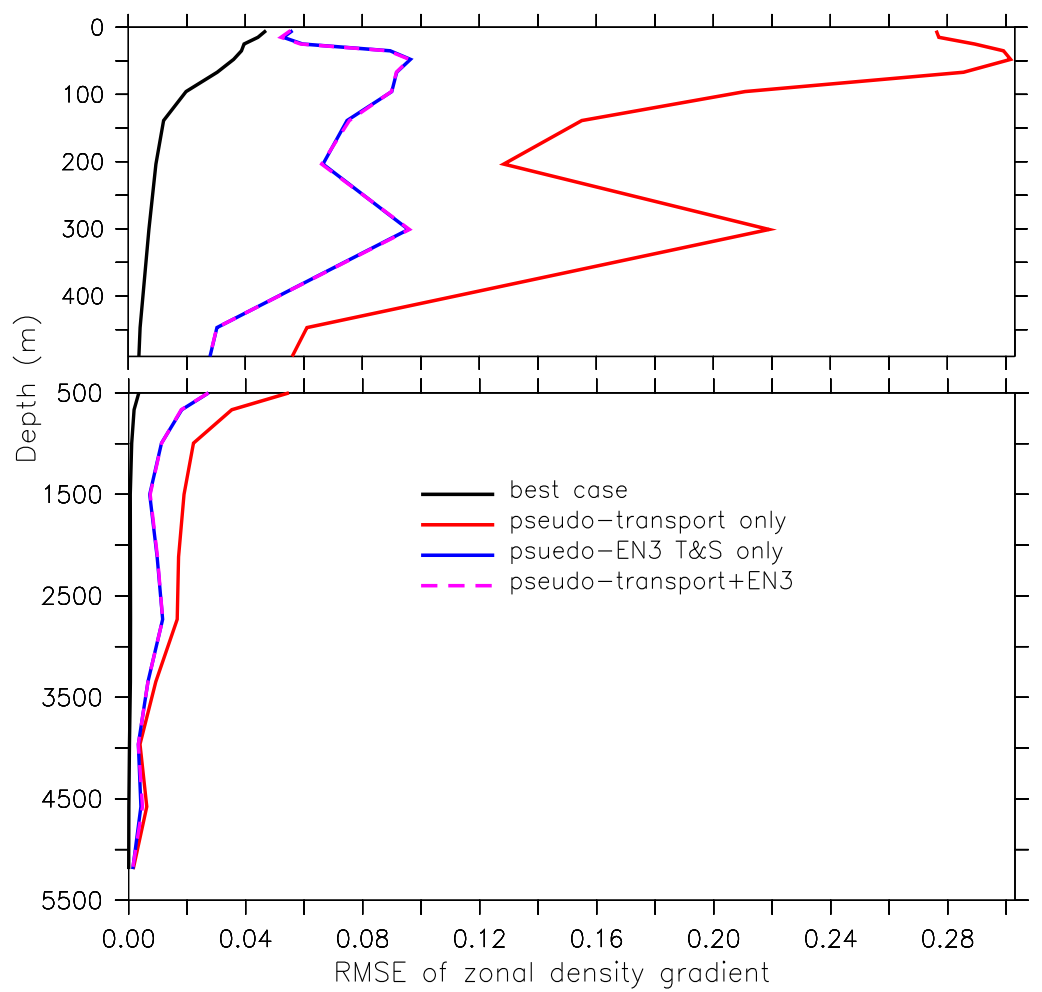

Figure 6: RMSE of the monthly mean zonal gradient profile $\left(\mathrm{kg} / \mathrm{m}^{3}\right)$, colours of lines as in Figure 5 .

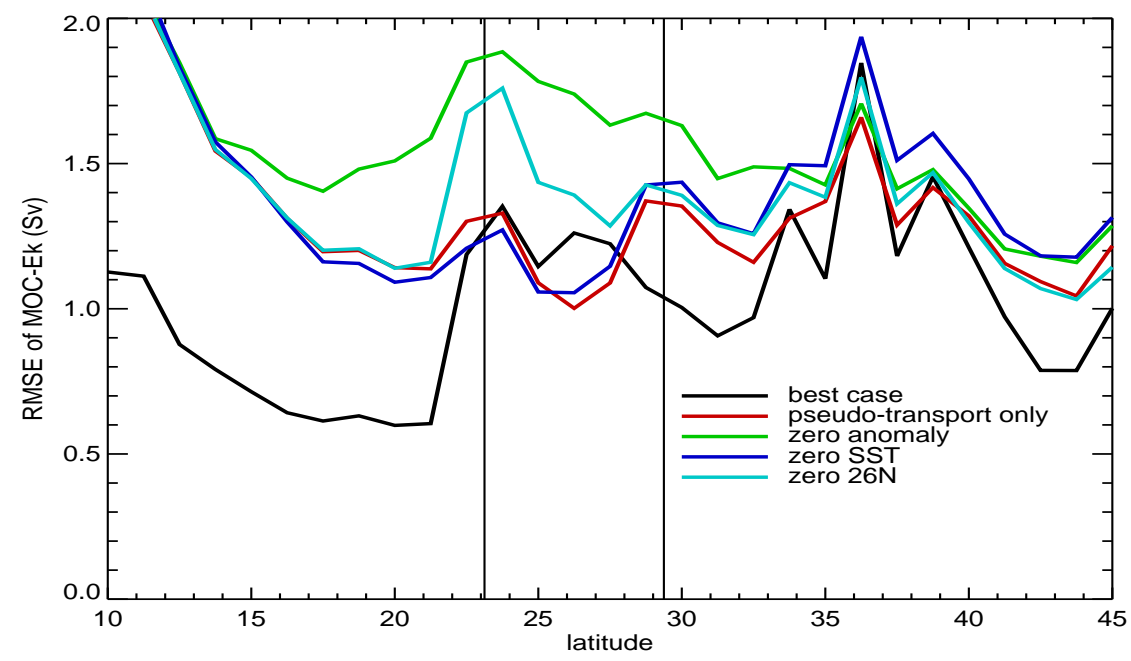

Figure 7: RMSE of monthly mean MOC-Ek for several assimilations, inlcuding one that is like pseudotransport-only except the SST is replaced with climatology (zero SST) and one also like pseudo-transportonly except climatology has been inserted at all depths for the latitudes surrounding $26^{\circ} \mathrm{N}$ as indicated by the vertical lines (zero $26 \mathrm{~N}$ ) 


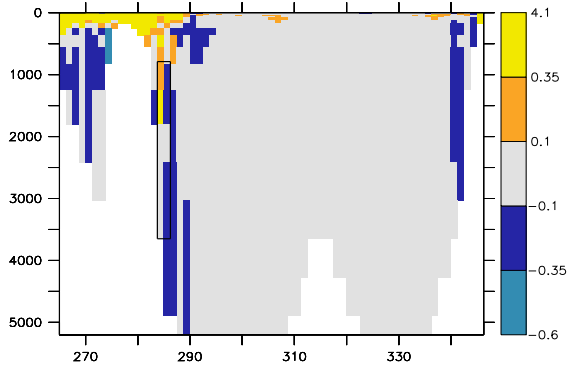

(a) RMSE difference

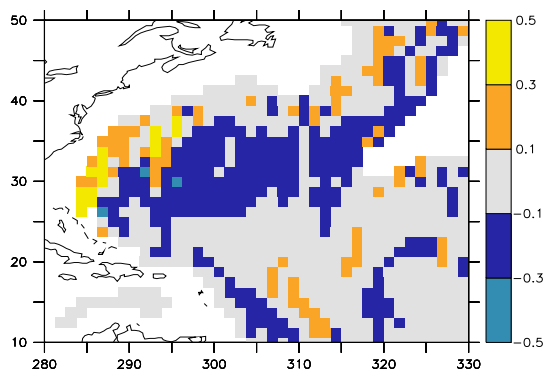

(b) Velocity correlation

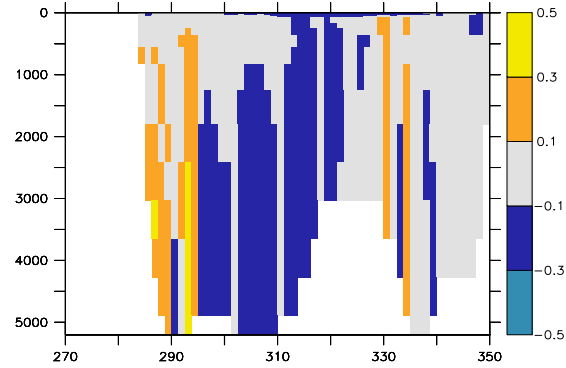

(c) Velocity correlation

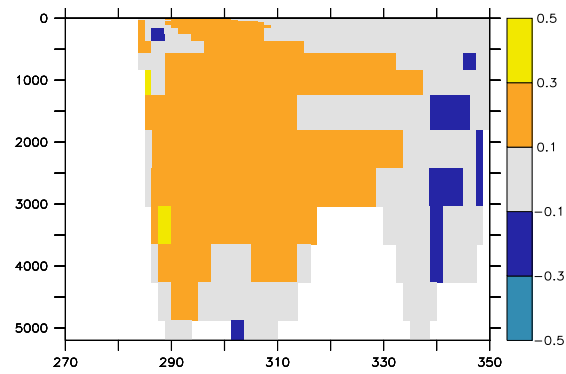

(d) density correlation

Figure 8: (a) Difference in RMSE of monthly means between the transport-only and EN3-only assimilations for meridional velocity at $26^{\circ} \mathrm{N}$. Negative values indicate that transport-only has lower error. Note that the contours are irregular. (b) Mean correlation between the southward branch of the MOC at $26^{\circ} \mathrm{N}$ , as indicated by the box in (a), and meridional velocity at $3400 \mathrm{~m}$. (c) As (b), but for a cross-section at $34^{\circ} \mathrm{N}$. (d) Mean correlation of density at $34^{\circ} \mathrm{N}$ with MOC minus Ekman transport at $26^{\circ} \mathrm{N}$. 